University of Wollongong

Research Online

Faculty of Social Sciences - Papers (Archive) Faculty of Arts, Social Sciences \& Humanities

2014

PACE: A group randomised controlled trial to increase children's break-time playground physical activity

Anne-Maree Parrish

University of Wollongong, aparrish@uow.edu.au

Anthony D. Okely

University of Wollongong, tokely@uow.edu.au

Marijka Batterham

University of Wollongong, marijka@uow.edu.au

Dylan P. Cliff

University of Wollongong, dylanc@uow.edu.au

Christopher A. Magee

University of Wollongong, cmagee@uow.edu.au

Follow this and additional works at: https://ro.uow.edu.au/sspapers

Part of the Education Commons, and the Social and Behavioral Sciences Commons

Research Online is the open access institutional repository for the University of Wollongong. For further information contact the UOW Library: research-pubs@uow.edu.au 
PACE: A group randomised controlled trial to increase children's break-time playground physical activity

\author{
Abstract \\ Abstract presented at Be Active 2014, 15-18 October 2014, Canberra, Australia. \\ Keywords \\ increase, trial, controlled, activity, randomised, physical, break, pace, playground, time, group, children \\ Disciplines \\ Education | Social and Behavioral Sciences

\section{Publication Details} \\ Parrish, A., Okely, A., Batterham, M., Cliff, D. \& Magee, C. (2014). PACE: A group randomised controlled trial \\ to increase children's break-time playground physical activity. Journal of Science and Medicine in Sport, \\ 18 (Supplement 1), e64-e64.
}




\title{
PACE: A group randomised controlled trial to increase children's break-time playground physical activity
}

\author{
A. Parrish, A. Okely, M. Batterham, D. Cliff, C. Magee \\ University of Wollongong, Australia
}

Introduction: Physical activity provides positive health benefits for children, although many are insufficiently active. The school recess environment offers opportunities for most children to be active. Evidence suggests that environmental and policy changes can increase children's school recess activity levels. The aim of this study was to assess the effect of an intervention that modified the school playground environment and policies addressing physical activity levels among school-aged children during recess.

Methods: Two-arm parallel group randomised controlled trial. Children aged 4-13 years from four primary/elementary schools in the Illawarra region of New South Wales, Australia participated in the study. Intervention schools introduced policy changes and assigned a donated quantity of portable equipment to recess after baseline measures were collected. The intervention ran between three and five months. Physical activity was assessed using the System for Observing Playground Activity in Youth (SOPLAY) observational instrument. Linear mixed models adjusting for the clustering effect of school. Effect sizes were calculated using an adjustment of the methods proposed by Hedges.

Results: 1582 children participated (790 boys, 792 girls). Compared with students in the control schools, there was a greater increase in the proportion of time spent in MVPA during recess among students in the intervention schools at follow-up (adjusted difference $=12.5 \%, 95 \% \mathrm{Cl}[-13.0 \%, 38.0 \%] ; P=0.17 ; r=0.6)$. Most of this increase was attributed to a significantly greater increase in MVPA during morning break time among students in intervention schools (adjusted difference $=18.0 \%, 95 \% \mathrm{Cl}[6.9 \%, 29.1 \%]$; $P=0.02 ; r=0.7)$. The results were greater for girls compared to boys.

Discussion: Our results suggest that making several small environmental and policy changes such as removal of forced sitting time at the start of recess, and providing portable play equipment is a promising strategy for promoting health-enhancing physical activity during recess. 